\title{
Erratum to: MDCT diagnosis of post-traumatic hepatic arterio-portal fistulas
}

\section{Cuong T. Nguyen • Nitima Saksobhavivat • \\ Kathirkamanathan Shanmuganathan • \\ Scott D. Steenburg • Fred M. Moeslein • \\ Stuart E. Mirvis - William Chiu \\ Published online: 10 March 2013 \\ (C) Am Soc Emergency Radiol 2013 \\ Erratum to: Emerg Radiol \\ DOI 10.1007/s10140-012-1092-6}

The original version of this article, unfortunately, contained errors.

1. The middle initials for the first, fourth, and fifth authors were missing. Their complete names are Cuong T. Nguyen, Scott D. Steenburg, and Fred M. Moeslein.
2. Cuong T. Nguyen and Nitima Saksobhavivat's names were incorrectly spelled to "Coung" and "Saksobahavivat," respectively, in the original. The correct spelling is reflected in this article.

3. The correct publication year for reference [8] is " 2008 " and not " 008 ". The correct reference is: Marmery H, Shanmuganathan K, Mirvis SE et al (2008) Correlation of multidetector CT findings with splenic arteriography and surgery: prospective study in 392 patients. J Am Coll Surg 206(4):685-693.
The online version of the original article can be found at http://dx.doi.org/ 10.1007/s10140-012-1092-6.

\section{N. Saksobhavivat}

Department of Radiology, Faculty of Medicine Ramathibodi

Hospital, Mahidol University, Bangkok,

10400 Bangkok, Thailand

K. Shanmuganathan $(\bowtie)$

Department of Diagnostic Radiology \& Nuclear Medicine,

University of Maryland Medical Center,

22 S. Greene Street,

Baltimore, MD 21201, USA

e-mail: kshanmuganathan@umm.edu

C. T. Nguyen · S. D. Steenburg · F. M. Moeslein · S. E. Mirvis

Department of Diagnostic Radiology and Nuclear Medicine,

University of Maryland, Baltimore, MD, USA

\section{W. Chiu}

Division of Critical Care, Program in Trauma, R. Adams Cowley

Shock Trauma Center, University of Maryland Medical Center,

22 S. Greene Street,

Baltimore, MD 21201, USA 